\title{
A PRODUÇÃO DE VIDEOAULAS NA LÍNGUA BRASILEIRA DE SINAIS: AS DESCOBERTAS DE UMA EQUIPE DE EXTENSIONISTAS QUE ACREDITAVA QUE TUDO ESTAVA CONSOLIDADO
}

\author{
Dra. Maria José Baldessar ${ }^{1}$ \\ Tânia Machado de Andrade ${ }^{2}$
}

\begin{abstract}
Resumo
Este artigo trata do projeto de extensão "Produção de Videoaulas para o curso de Licenciatura em Letras na Língua Brasileira de Sinais", desenvolvido por uma equipe de estudantes de Jornalismo e Design da Universidade Federal de Santa Catarina, coordenado pela professora Maria José Baldessar. Mostra os desafios enfrentados pelo grupo no entendimento de uma língua "estranha" ao cotidiano e na compreensão de conceitos abrangentes da área de Letras. Traz, ainda, considerações sobre a importância da extensão na relação universidade/comunidade como fundamental na formação acadêmica/cidadã dos alunos.
\end{abstract}

Palavras-chave: Linguagem jornalística. Produção televisiva. Cognição. Som.

\section{THE PRODUCTION OF VIDEO LESSONS IN BRASILIAN SIGN LANGUAGE}

\section{-LIBRAS: THE FINDINGS OF A TEAM OF EXTENSION WORKERS WHO}

\section{BELIEVED THAT EVERYTHING WAS CONSOLIDATED}

\begin{abstract}
This article presents the extension project "Production of video lectures for the Undergraduate Program in Brazilian Sign Language", developed by a team formed by professionals and students of Journalism and Design from Federal University of Santa Catarina and coordinated by Professor Maria José Baldessar. It shows the challenges faced by the group during the understanding of a "strange" language and also in the comprehension of broad concepts from the Program's field. It also brings considerations about the importance of extension in the relationship between university and community and as an essential piece in the student's academic/citizen formation.
\end{abstract}

Keywords: Journalistic language. Television production, Cognition, Sound.

\footnotetext{
1 Professora do Curso de Jornalismo da Universidade Federal de Santa Catarina, atualmente coordenadora do projeto de extensão Letras/Libras e do site www.cotidiano.ufsc.br.

2 Jornalista. Coordenadora de produção dos vídeos do Curso de Licenciatura e Bacharelado em Letras LIBRAS
}

\section{(i) (8)}

Esta obra está licenciada sob uma Licença Creative Commons. 


\section{INTRODUÇÃO}

As universidades brasileiras enfrentam uma série de desafios na atualidade: inclusão, ampliação de vagas, melhoria da qualidade e prestação de contas à sociedade de suas ações como formadora não somente de mão de obra qualificada, mas também, de cidadãos.

Uma das formas encontradas para dar resposta a estes desafios está no desenvolvimento de ações de extensão, considerada por alguns como o pilar "mais fraco" do tripé ensino, pesquisa e extensão, preconizado por boa parte das universidades públicas e privadas do país. Se, para estas, em especial, as federais, a extensão é uma forma de retorno à sociedade - através de cursos, programas de formação ou ações profissionais, para as privadas, é vitrine de sua qualidade e cursos.

Neste artigo, vamos relatar as experiências vividas pela equipe do Projeto "Produção de materiais em vídeo para o curso de graduação em Letras/Libras na modalidade a distância e os desafios enfrentados por ela, sob forma de extensão. Cabe salientar, que, como professora e pesquisadora, sempre estive ligada a projetos de extensão desde a minha chegada na Universidade Federal de Santa Catarina. Ao analisar cada um e verificar a possibilidade de um artigo acerca do conjunto desses trabalhos e de um especial, escolhi o Letras/Libras por considerar que ele responde a alguns dos desafios das universidades públicas brasileiras, citados no início deste relato.

Ao contrário do que diz o velho provérbio que "Uma imagem vale mais que mil palavras" a produção de videoaulas para o curso de Licenciatura em Letras, na Língua Brasileira de Sinais, tem mostrado que as palavras e os sons fazem falta e, muita.

Em 2006, a UFSC criou o curso de graduação Licenciatura em Letras, na modalidade a distância, em Libras - a Língua Brasileira de Sinais $^{3}$, que integra as políticas de inclusão social e de diversidade da instituição. A criação responde ao

\footnotetext{
${ }^{3}$ Objetivo geral: Formar professores para atuar no ensino da língua de sinais como primeira e segunda língua. Objetivos específicos: examinar o desenvolvimento histórico e cultural da comunidade surda brasileira e da educação de surdos no Brasil; compreender o processo de aquisição da linguagem; relacionar o processo de aquisição da linguagem com o ensino de primeira e segunda língua; analisar os aspectos lingüísticos relacionados à Língua Brasileira de Sinais; desenvolver propostas metodológicas para o ensino da Língua Brasileira de Sinais como primeira e segunda língua, explorando as atuais tecnologias de comunicação.
} 
A Produção de Videoaulas na Lingua Brasileira de Sinais: as Descobertas de uma Equipe de Extensionistas que Acreditava que tudo Estava Consolidado

reconhecimento da cultura surda, respaldada na Lei $10.436^{4}$, de 24 de abril de 2002 e regulamentada pelo Decreto 5.628, de 22 de dezembro de 2005, e está sendo desenvolvida pela Secretaria de Educação a Distância juntamente com o Centro de Comunicação Expressão, tendo também como parceiro o Centro de Ciências da Educação. Hoje, além da Licenciatura, já conta com habilitação em Bacharelado.

O Curso de Licenciatura e Bacharelado em Letras - LIBRAS é, em rede nacional, na forma de convênio com outras 18 Instituições de Educação, tem cerca de 1200 alunos, sendo que a maioria tem deficiência auditiva significativa. ${ }^{5}$ Atualmente, além da modalidade a distância, a UFSC oferece o curso presencial - com entrada anual de 60 alunos.

Inédito na América Latina, o Libras, como é conhecido, trouxe para o grupo de professores envolvidos na produção de materiais didáticos desafios e questionamentos sobre o ensinar uma língua não consolidada e mutante ${ }^{6}$. É nesse contexto que está inserida a equipe do curso de Jornalismo encarregada de produzir 28 videoaulas e, ao longo do projeto, teve de refazer discussões, rever padrões e contrapor assertivas sobre linguagem visual e televisiva, conteúdos obrigatórios dos currículos de Jornalismo, a saber: como produzir vídeos sem som (música ou palavra) e sem caracteres? (exigências estabelecidas no projeto pedagógico do Letras/Libras)? Qual linguagem utilizar para traduzir conceitos da linguística, semiótica, literatura, se a equipe é formada por profissionais e estudantes de Jornalismo e Design que não conhecem em profundidade esses conceitos? Como dar complexidade teórica a uma videoaula sem banalizar exemplos e citações? E mais, como traduzir sons inscritos no nosso imaginário ouvinte para quem nunca ouviu?

\section{As descobertas}

A nossa primeira descoberta: as palavras e os sons fazem falta na comunicação humana. As imagens, antes mesmo da fala, são meios de expressão do homem desde há

\footnotetext{
4 - http://www.planalto.gov.br/ccivil_03/Leis/2002/L10436.htm

5 - A análise das demandas foi feita a partir dos indicadores apresentados no Censo Educacional de 2004. Pelo Censo, havia 24.577.000 pessoas com necessidades especiais, sendo que destes 16,7\% são surdos e, entre estes, 2.600 .000 necessitam de atendimento em todos os níveis escolares. A distribuição geográfica dessa população está atrelada à distribuição da população em geral.

6 - A Linguagem Brasileira de Sinais foi reconhecida em 2002 e, tal como outras línguas, no decorrer de seu uso vão incorporando novas expressões e apropriando novos termos, inclusive os regionais. Por isso é uma língua em construção.
} 
A Produção de Videoaulas na Lingua Brasileira de Sinais: as Descobertas de uma Equipe de Extensionistas que Acreditava que tudo Estava Consolidado

muito tempo. Os escritos rupestres, deixados em cavernas e formações rochosas, eram formas de o homem primitivo se relacionar com outros e, consequentemente, com universo. No jornalismo, a imagem aparece sob diversos gêneros como a fotografia, vídeo e, agora, com as novas tecnologias com holografia, infografia e fotografia computacional. No entanto, os sons complementam aquilo que não é possível visualizar, os sons expressam, muitas vezes, mais sentimentos que imagens e gestos.

Para Benvemiste (apud SANTAELLA, 1999) as imagens são um "sistema semiótico ao qual falta uma metassemiótica", ou seja, segundo o pesquisador, elas não podem servir como meios de reflexão sobre si próprias, sendo necessária a interferência do discurso verbal para a elaboração de uma teoria da imagem. No entanto, lembra-nos Santaella (1999, p. 14), o código verbal não pode se desenvolver sem imagens: "O próprio termo 'teoria' vem do grego theorein, que significa 'ver, olhar, contemplar ou mirar'; o que corrobora com a afirmação de que 'nosso discurso verbal está permeado de iconicidade','.

Nos dias de hoje, é comum ouvirmos a expressão geração da imagem, pois ela se mostra coerente com um mundo onde cinema, televisão, jornal, livro, revista trazem imagens como fatores de agregação de público e mais valia a informação. Por outro lado, o som está incorporado em nossas vidas e a experiência do silêncio - embora no radiojornalismo seja uma estratégia para chamar a atenção, confunde-nos e nos leva a um estado reflexivo e mais atento. E, nesse ponto, discordamos de Raymond Bellour (1996, p. 218) para quem "as imagens precedem o mundo, multiplicando elas mesmas os mundos até o indiscernível, [...] mas é o olho que assegura o elo entre o mundo e suas imagens, visto que é ele que os percebe".

Pensar as potencialidades das linguagens digitais, os efeitos trazidos pelos meios tecnológicos contemporâneos, a exploração dos seus recursos e a criação de novas interfaces é fundamental neste momento culminante do avanço tecnológico. Contemplar questões referentes a mudanças de paradigmas na produção de som e imagem é ponto crucial para o entendimento das novas configurações imagéticas. Pois, quando estes migram para o domínio das novas tecnologias digitais e passam a habitar em redes telemáticas, transportam-nos para um universo desprovido de películas ou telas que possam ser contempladas e nos obrigam a imergir através de um ideal interativo, seja ele na busca de uma nova língua ou na inserção a uma sociedade excludente. 
A Produção de Videoaulas na Lingua Brasileira de Sinais: as Descobertas de uma Equipe de Extensionistas que Acreditava que tudo Estava Consolidado

Não podemos esquecer que, embora a imagem nos mostre o real, o som nos faz viajar no nosso imaginário, criando paisagens próprias e únicas. E aí está mais uma descoberta: como falar para quem uma parte do imaginário sempre se ligou ao visual, à imagem e que, por conta da natureza, teve abstraída a capacidade de reproduzir paisagens próprias, advindas da apreensão da realidade através da língua, da música, dos sons da natureza?

Para além das considerações sobre tecnologia, áudio e vídeo, o desenvolvimento de um projeto de extensão com esse caráter - produção de material permanente para a formação associado à questão da inclusão de uma gama de cidadãos normalmente alijados da educação superior - trouxe para a equipe envolvida reflexões importantes: (1) associar um conhecimento próprio da área na construção de um projeto de inclusão social; (2) a extensão como forma de relacionamento com os diferentes; (3) uma resposta social importante à obtenção e difusão do conhecimento.

\section{Equipe}

A equipe do Letras/Libras/Jornalismo é formada por duas jornalistas profissionais, incumbidas do roteiro e produção executiva; cinco alunos da $4^{\circ}, 5^{\circ} \mathrm{e} 6^{\circ}$ fase do curso de Jornalismo que pesquisam imagens e materiais gráficos colaboram na elaboração do roteiro e fazem a edição e finalização; um aluno do Design que faz artegrafismo e vinhetagem; três cinegrafistas profissionais, responsáveis pelas imagens tanto de estúdio como as externas; um intérprete de sinais - aluno de pós-graduação em Educação e librista fluente e um professor-coordenador.

O projeto foi finalizado em junho de 2010 e produziu 87 programas diferentes, todos na Língua Brasileira de Sinais, e que serão disponibilizados no repositório de materiais educativos do Ministério da Educação.

\section{O processo de produção}

A produção de uma videoaula inicia com a definição da disciplina e do conteúdo a ser trabalhado no DVD pelo professor responsável por ela - todo o conteúdo referente às 60 horas aulas ou a exploração de um conceito, personagem. Por exemplo, em Introdução aos Estudos de Literatura, o professor optou por um DVD temático sobre 
A Produção de Videoaulas na Lingua Brasileira de Sinais: as Descobertas de uma Equipe de Extensionistas que Acreditava que tudo Estava Consolidado

Machado de Assis e a literatura no Brasil império. Feitas as escolhas, a equipe de produção se reúne com o professor para um brainstorm. Anotadas as ideias e sugestões, passa-se para um cronograma rigoroso de produção do roteiro e produção. Depois, em estúdio ou externas, é gravado o programa traduzido em Libras, ou seja, o interprete dá aos atores os tempos de gravação, analisa a qualidade do gesto e da composição final da imagem.

Ressalte-se que, nesse ponto de produção, tivemos mais surpresas. As sombras, cor de pele, cor de roupa influenciam na atenção do aluno librista e, dependendo da composição apresentada, ele não consegue captar a expressão gestual, que muitas vezes é marcada pelo "sotaque" / "fala" do tradutor. Então, é nessa etapa que o trabalho demanda mais cuidado e precisão, já que a compressão e apreensão do conteúdo são indispensáveis para a continuidade do aluno na universidade.

\section{CONSIDERAÇÕES FINAIS}

A experiência com o Letras/Libras tem mostrado a nós, equipe de produção, que muito do que considerávamos consolidado em relação a roteiro, linguagem televisiva, exploração de materiais alternativos está em aberto e necessitando de projetos que desafiem o pronto.

Para os alunos de Jornalismo e Design, a experiência tem se mostrado rica na afirmação de conhecimentos, aprofundamento de outros, capacidade de integração com os "diferentes" e compreensão de outras realidades às quais não estão/estamos acostumados. Outra percepção: o trabalho entre profissionais e os alunos tem permitido a troca de experiências sobre o mercado e trabalho e as opções que este oferece para quem tem uma formação sólida em diversas áreas.

Finalmente, para toda a equipe, há a satisfação de contribuir num projeto de valor social incalculável, que trouxe para dentro de universidade pessoas antes excluídas dela - seja por sua condição social, seja por sua condição de "diferente".

\section{REFERÊNCIAS}

BELLOUR, Raymond. Entre-imagens. Foto. Cinema. Vídeo. SP, Papirus, 1996.

SANTAELlA, L., O que é Semiótica, São Paulo: Brasiliense, 1999. 